postoperative DVT is three times greater if they are undergoing hip rather than abdominal surgery, but this takes no account of the age difference between the two groups. Evidently, however, chronic venous insufficiency detected by an abnormal AET doubles the risk of developing DVT in the already high-risk condition of elective hip surgery.

After-exercise thermography is the first objective and noninvasive prognostic test for assessing the risk of postoperative DVT. Prophylaxis is mandatory when the result is positive. Our findings show that previous thromboembolism is a positive indication for prophylaxis, and that the combination of treated or untreated varicose veins and an abnormal AET carries a very high risk. Varicose veins together with a normal AET do not appear to increase the risk of postoperative DVT significantly. Thus varicose veins are not an absolute indication for prophylaxis ${ }^{7}$ unless they are secondary to damage in the deep or communicating veins.

Though there was a close correlation between phlebographically confirmed venous damage and an abnormal AET, in a few cases with an abnormal AET the phlebographic appearances of the deep and communicating veins were normal. The reverse was not found. This suggests that an AET is a more sensitive indicator of venous function than a phlebogram.

The table, which gives the siting of thrombi in relation to the appearance of the AET, shows that a leg for which there is an abnormal AET may well develop a thigh-vein thrombus without any associated DVT of the calf, suggesting that the basic condition is common to or affects both calf and thigh veins.

Our findings concur with our belief that the AET provides an estimate of the efficiency of the calf-muscle pump and that an abnormal AET indicates some degree of failure. Patients with this condition may well have changes in the vessel walls that predispose to thrombosis, and they may suffer more profound and prolonged postoperative stasis, a long-recognised ${ }^{8}$ and important facultative factor ${ }^{9-11}$ in the pathogenesis of venous thrombosis.

We thank Aga Infrared Systems AB; Philips Medical Ltd; J and P Engineering; Mr A Stockley, department of medical physics at Southend General Hospital; Miss Jane Wadsworth, department of computer medical sciences at St Bartholomew's Hospital; and the consultants and staff of Basildon and Bethnal Green hospitals.

\section{References}

1 Cooke, E D, and Pilcher, M F, British fournal of Surgery, 1974, 61, 971.

2 Cooke, E D, and Pilcher, M F, British Medical fournal, 1973, 2, 523.

3 Gordon, Y B, et al, British fournal of Haematology, 1977, 35, 503.

4 Kakkar, V V, et al, Lancet, 1970, 1, 540.

5 Lea Thomas, M, McAllister, V, and Tongue, K, Clinical Radiology, 1971, 22, 490.

6 Williams, W J, Circulation, 1973, 47, 220.

${ }^{7}$ Kakkar, V V, et al, American fournal of Surgery, 1970, 120, 527.

${ }^{8}$ Virchow, R, Cellular Pathology as based upon Physiological and Pathological Histology, trans F Chance. London, Churchill, 1860.

9 Roberts, V C, and Cotton, L T, British Medical fournal, 1974, 1, 358.

10 Roberts, V C, and Cotton, L T, British Medical fournal, 1975, 3, 458.

11 Stewart, G J, in Thromboembolism, ed A N Nicolaides, p 101. Lancaster, MTP Press, 1975.

(Accepted 13 February 1978)

\title{
Chlamydia trachomatis as possible cause of peritonitis and perihepatitis in young women
}

\author{
J W MÜLLER-SCHOOP，S P WANG，J MUNZINGER， H U SCHLÄPFER， M KNOBLAUCH, \\ R W AMMANN
}

British Medical fournal, 1978, 1, 1022-1024

\section{Summary and conclusions}

Of 11 young women with acute peritonitis proved by laparoscopy, seven of whom also had perihepatitis, nine had serological evidence of recent infection with Chlamydia trachomatis. In five of these nine patients high antibody titres to chlamydiae were found without laboratory evidence of gonococcal infection, while the other four had evidence of simultaneous gonococcal infection.

\footnotetext{
Department of Medicine, Kantonsspital, University of Zürich, Zürich, Switzerland

J W MÚLLER-SCHOOP, MD, senior resident

$R$ W AMMANN, MD, professor of gastroenterology

$M$ KNOBLAUCH, MD, lecturer in gastroenterology

School of Public Health and Community Medicine, Department of Pathobiology, University of Washington, Seattle, USA

S P WANG, MD, DR MED SCI, professor

Institute for Medical Microbiology, University of Zürich, Switzerland J MUNZINGER, MD, head of laboratory

Spital, Wädenswil, Switzerland

H U SCHLÄPFER, MD, senior resident
}

C trachomatis may play an important part in peritoneal inflammation previously attributed only to gonococci.

\section{Introduction}

Acute fibrinous perihepatitis (Fitz-Hugh-Curtis syndrome) has been described as an unusual complication of gonococcal pelvic inflammatory disease that typically occurs in young, sexually active women. ${ }^{12}$ In our experience the disease may not be so rare, ${ }^{3}$ and may pose considerable diagnostic problems, especially when symptoms and findings are indistinguishable from acute cholecystitis. In difficult cases laparoscopy is an efficient way of establishing the correct diagnosis. Between September 1976 and July 1977 fibrinous perihepatitis was diagnosed by laparoscopy in seven women admitted to the Kantonsspital, Zürich. Four other young women with similar symptoms were found to have diffuse peritonitis without inflammation of the liver capsule.

The unexpected finding of a very high titre to chlamydiae in one of the women without signs of gonococcal infection prompted us to investigate all the patients for gonococcal as well as chlamydial infection, an important cause of nongonococcal urethritis in men, ${ }^{45}$ and associated with a high proportion of cases of acute salpingitis in women. ${ }^{6}$ Although no methods for culturing chlamydiae were available then in our hospital, the serological findings in our patients seemed impressive enough to warrant reporting them. 


\section{Patients and methods}

Of the 11 women patients, 10 were admitted to the surgical or medical departments of the Kantonsspital, Zürich, and one (case 2) was seen at the Spital Wädenswil. All had acute abdominal pain, but because of only discrete or moderate signs of peritonitis and uncertainty about the diagnosis laparotomy was usually deferred and further diagnostic procedures were undertaken. All the women underwent a gynaecological examination performed by an experienced gynaecologist. Laparoscopy was performed in all cases, the laparoscope being introduced above the umbilicus, which permits inspection of the liver and upper peritoneal situs. All the women were sexually active, and only one (case 2) was married. Of the four women who were lost to serological follow-up studies, two worked as night-club dancers and one was a part-time prostitute.

Evidence for gonococcal infection was sought by cultures from the cervix, and from ascites when obtainable, and by serology. Cervical swabs were directly inoculated on to plates coated with ThayerMartin medium, and the growth of gonococci was verified by routine biochemical methods. Measurement of antibody titres to gonococcal antigens was performed by complement fixation using glycineextracted gonococcal antigens. Antibodies to cytomegalovirus, herpes simplex, and chlamydiae were detected by complement fixation. For more precise chlamydial serology, the sera were examined by one of us (SPW) using the microimmunofluorescence test to detect antibodies to $C$ trachomatis immunotypes. ${ }^{7}$ After preliminary screening, positive sera were further tested concurrently for IgM and IgG antibodies with the standard test, ${ }^{8}$ using twofold dilutions and 14 separate antigens, including those of lymphogranuloma venereum. The first serum samples were usually taken shortly after admission, and the second two to three weeks later. The delay between the onset of symptoms and admission to hospital varied from a few days in three patients (cases 7,8 , and 11) to four weeks in two (cases 1 and 2).

\section{Results}

Table I shows the laparoscopic findings, results of gynaecological examinations, leucocyte counts, and erythrocyte sedimentation rates in the 11 women. Ascites was present in sufficient quantities to allow examination in six patients (cases 1, 2, 6, 7, 9, and 10). Ascitic cultures were sterile in all cases, and regularly contained granulocytes, mesothelial cells, and lymphocytes. Two women (cases 1 and 4) had diffuse peritonitis without any signs of salpingitis or perihepatitis (table I). Seven patients had perihepatitis, and only two salpingitis. Six of the seven patients found to have perihepatitis at laparoscopy showed the characteristic adhesions between the liver capsule and the parietal peritoneum, some having the typical violin-string appearance (see fig).

The results of laboratory tests for $C$ trachomatis and Neisseria gonorrhoeae infections in the 11 patients are shown in table II. $C$ trachomatis antibodies were observed in all except one (case 11). The patients had type-specific antibodies to trachoma immunotypes (B, D, E, F, G, I, and J), but not to lymphogranuloma venereum. IgM antibodies indicative of recent infection were found in seven patients, and a definite change in antibody titre (rise or fall) was observed in four of the six pairs of sera that were available for testing on more than one occasion. Extremely high titres (1/2048 or more) of IgG antibodies were observed in six patients. Except for patients with lymphogranuloma venereum, antibody titres greater than $1 / 1024$ are rarely detected, even in a laboratory with extensive experience. ${ }^{7}$

TABLE I-Clinical data on 11 women with peritonitis and perihepatitis or salpingitis, or both

\begin{tabular}{|c|c|c|c|c|c|c|}
\hline $\begin{array}{c}\text { Case } \\
\text { No }\end{array}$ & $\underset{\text { (years) }}{\text { Age }}$ & Peritonitis* & Perihepatitis & Salpingitis & $\begin{array}{l}\underset{(\mathrm{mm} \text { in }}{\text { ESR }} \\
\text { first } \mathrm{h})\end{array}$ & $\begin{array}{c}\text { Leucocyte } \\
\text { count } \\
\left(\times 10^{\%} / 1\right)\end{array}$ \\
\hline $\begin{array}{r}1 \\
2 \\
3 \\
4 \\
5 \\
6 \\
7 \\
8 \\
9 \\
10 \\
11\end{array}$ & $\begin{array}{l}36 \\
31 \\
18 \\
25 \\
24 \\
23 \\
26 \\
18 \\
38 \\
26 \\
17\end{array}$ & $\begin{array}{l}+ \\
+ \\
+ \\
+ \\
+ \\
+ \\
+ \\
+ \\
+ \\
+ \\
+\end{array}$ & $\begin{array}{l}+ \\
+ \\
+ \\
+ \\
+ \\
+ \\
+\end{array}$ & $\begin{array}{l}+ \\
+\end{array}$ & $\begin{array}{r}58 \\
56 \\
55 \\
40 \\
50 \\
2 \\
46 \\
45 \\
11 \\
21\end{array}$ & $\begin{array}{r}8 \cdot 8 \\
9 \cdot 5 \\
7 \cdot 2 \\
9 \cdot 1 \\
12 \cdot 7 \\
12 \cdot 5 \\
14 \cdot 0 \\
14 \cdot 6 \\
16 \cdot 0 \\
9 \cdot 1 \\
12 \cdot 8\end{array}$ \\
\hline
\end{tabular}

-Diffuse peritonitis or peritonitis confined to right upper quadrant. ESR = erythrocyte sedimentation rate.

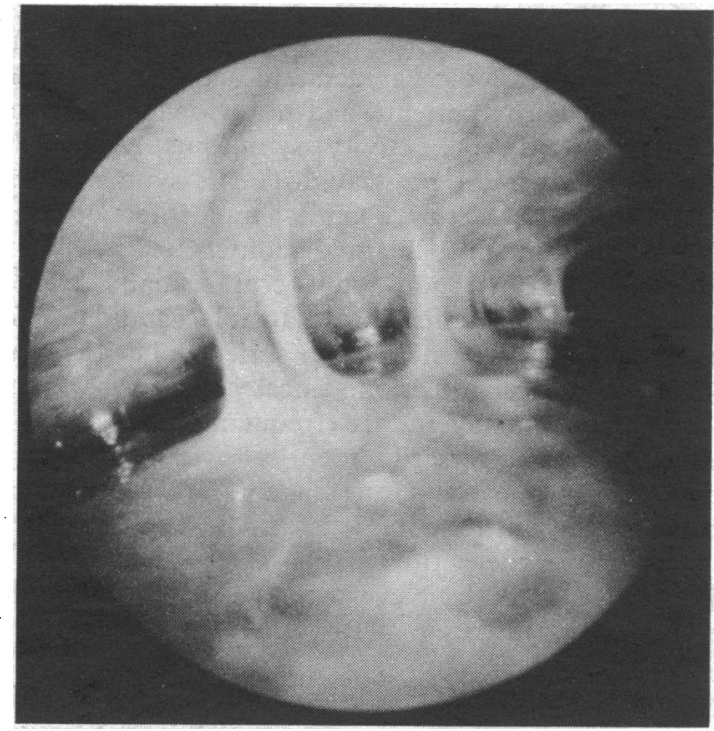

Case 2. Laparoscopic view of right upper quadrant in patient with perihepatitis showing adhesions between liver capsule and parietal peritoneum.

TABLE II-Results of laboratory tests for Chlamydia trachomatis and Neisseria gonorrhoeae infections in 11 women with peritonitis

\begin{tabular}{|c|c|c|c|c|c|}
\hline \multirow{2}{*}{$\begin{array}{l}\text { Case } \\
\text { No }\end{array}$} & \multirow{2}{*}{$\begin{array}{l}\text { Days after } \\
\text { onset of } \\
\text { disease }\end{array}$} & \multicolumn{2}{|c|}{$\begin{array}{l}\text { C trachomatis (micro- } \\
\text { immunofluorescence)* }\end{array}$} & \multicolumn{2}{|c|}{ N gonorrhoexe } \\
\hline & & IgM & IgG & $\begin{array}{l}\text { Cervical } \\
\text { culture }\end{array}$ & $\begin{array}{l}\text { Complement } \\
\text { fixation } \dagger\end{array}$ \\
\hline $\begin{array}{r}1 \\
2 \\
3 \\
4 \\
5 \\
6 \\
7 \\
8 \\
9 \\
10 \\
11\end{array}$ & $\begin{array}{r}>60 \\
22 \\
49 \\
17 \\
52 \\
19 \\
36 \\
78 \\
94 \\
14 \\
0 \\
2 \\
15 \\
10 \\
12 \\
5 \\
27\end{array}$ & $\begin{array}{l}0 \\
0 \\
0 \\
\text { D } 256 \\
0 \\
\text { B } 128 \\
\text { B } 32 \\
0 \\
\text { F } 64 \\
\text { E } 64 \\
\text { I } 32 \\
\text { D } 64 \\
\text { D } 256 \\
\text { G } 64 \\
0 \\
0 \\
0\end{array}$ & $\begin{array}{l}\text { D } 2048 \\
\text { D } 2048 \\
\text { D } 2048 \\
\text { D } 8192 \\
\text { D } 2048 \\
\text { B } 2048 \\
\text { B } 2048 \\
\text { D } 1024 \\
\text { D } 512 \\
\text { F } 128 \\
\text { I } 128 \\
\text { G } 512 \\
\text { G } 2048 \\
\text { J } 32 / B 16 \\
\text { D } 64 \\
0 \\
0\end{array}$ & $\begin{array}{ll}- & \\
- & \{ \\
- & \{ \\
- & \{ \\
- & \{ \\
+ & \\
+ & \{ \\
- & \\
+ & \{\end{array}$ & $\begin{array}{r}0 \\
0 \\
0 \\
0 \\
0 \\
0 \\
0 \\
0 \\
0 \\
0 \\
6 \\
0 \\
12 \\
24 \\
12 \\
0 \\
0\end{array}$ \\
\hline
\end{tabular}

*Shown by immunotype(s) of antibedy response and titre (reciprocal of highest

serum dilution giving positive reaction to that immunotype); $0=<8$.
+ Complement fixation antibody titre; $0=<6$.

Different immunotype responses between IgM and IgG antibodies were observed in four patients (cases 5, 6, 8, and 9), which suggested previous infections with heterotype strains. Among the 10 patients positive for $C$ trachomatis antibody, five had laboratory evidence of infection with $\mathrm{N}$ gonorrhoeae; three by culture and two by complement fixation alone.

Four patterns of laboratory results were observed in the 11 patients. Five (cases 1-5) had strong serological evidence of recent acute $C$ trachomatis infection and neither cultural nor serological evidence of gonococcal infection. Four (cases 6-9) also had strong serological evidence of recent chlamydial infection, but in addition had evidence of past or current gonococcal infection. One patient (case 10) had serological evidence of past chlamydial infection and cultures were positive for $N$ gonorrhoeae. The remaining patient (case 11) had a clinically identical disease with that of the other women, but negative laboratory results for both chlamydial and gonococcal infections.

Antibody titres to cytomegalovirus and herpes simplex ranged from nil to $1 / 40$ in our patients; they did not differ greatly from those in an age-matched group of healthy women. Antibodies to chlamydiae were absent in 10 and positive at $1 / 20$ in one of the 11 healthy women in the control group. Low titres $(1 / 10-1 / 20)$ of antibodies to chlamydiae are found by complement fixation in about $13 \%$ of healthy people (blood donors) in the Zürich region. 


\section{Discussion}

Of these 11 women with perihepatitis or diffuse peritonitis, nine had excellent serological evidence of acute recent chlamydial infections. Five of the patients had no evidence of gonococcal infection. The age, sexual activity, symptoms, and the laparoscopic findings typical of Fitz-Hugh-Curtis syndrome in three of the women suggested that a genital tract infection may have spread to the peritoneum. Chlamydiae, increasingly found to be responsible for various non-gonococcal sexually transmitted diseases in men and women, are plausible candidates for this type of infection. Five women in our series had evidence of past or current gonococcal infection. Local genital tract infections with more than one agent are frequent, ${ }^{9}$ and the invading organisms are not necessarily identical with those cultivated from the cervical mucosa. Unless agents are cultured directly from the inflamed peritoneum, it is impossible in such cases to determine whether the peritonitis may have been due to one or the other agent or both. Nevertheless, the extremely high $C$ trachomatis antibody titres in many of our patients was suggestive of an aetiological association.

Only two of our 11. patients with peritonitis had.signs of salpingitis on gynaecological examination. If the assumption that our patients had genitally acquired infections is correct, probably the infectious agent ascending from the cervical canal often reaches the peritoneum without causing salpingitis. Equally, perihepatitis does not seem to be an invariable feature of the disease. Two patients (cases 1 and 4), both of whom had very high titres to chlamydiae, had neither salpingitis nor perihepatitis. These two cases show that evidence for genitally transmitted infections should be sought in all women with apparent "spontaneous" peritonitis.

Four of the nine women with signs of chlamydial infections were not treated with tetracycline but with antibiotics not thought to be active against chlamydiae (two with ampicillin, two with spectinomycin), yet their disease subsided within one to two weeks. Nevertheless, one patient (case 2) continued to be ill for weeks when taking ampicillin alone, but rapidly improved after receiving tetracycline. Hence chlamydial peritonitis may follow a benign course, but tetracyclines can accelerate recovery.

In sexually active women with various partners multiple $C$ trachomatis antibody types may be found. Studies on monkeys ${ }^{10}$ and experience with patients attending venereal-disease clinics showed that the original infecting type was often recalled after infection with a new type, and in the screening microimmunofluorescence test or with IgG conjugate the highest antibody titre was found against a previous immunotype rather than the current infecting type. ${ }^{7}$ If the organism cannot be isolated the use of the IgM conjugate helps to determine the current infecting type when multiple antibody types are present. Thus in three of our patients (cases 5,6 , and 8) the antibody type measured with IgM conjugate was probably the current infecting type.

We hope that our report will encourage clinicians and microbiologists to look for direct evidence of chlamydial infections in similar cases by culturing the agents from the inflamed sites.

We thank Dr J Thomas Grayston for his criticism and valuable suggestions and Dr U H Krech, St Gallen, Switzerland, for performing the complement fixation studies.

The study was partly supported by a United States Public Health Service research grant (EY-00219) from the National Eye Institute.

\section{References}

${ }^{1}$ Curtis, A H, Fournal of the American Medical Association; 1930, 94, 1221.

${ }^{2}$ Fitz-Hugh, T, Fournal of the American Medical Association, 1934, 102, 2094.

${ }^{3}$ Ammann, R, et al, Deutsche medizinische Wochenschrift, 1971, 96, 1515.

${ }^{4}$ Holmes, K K, et al, New England Fournal of Medicine, 1975, 292, 1199.

5 Schachter, J, et al, fournal of the American Medical Association, 1975, 231, 1252 .

${ }^{6}$ Mardh, P-A, et al, New England fournal of Medicine, 1977, 296, 1377.

${ }^{7}$ Wang, S P, in Nongonococcal Urethritis and Related Infections, ed D Hobson and K K Holmes, p 237. Washington DC, American Society for Microbiology, 1977.

8 Wang, S P, and Grayston, J T, Fournal of Infectious Diseases, 1974, 130, 388 .

9 Wentworth, B B, et al, Health Laboratory Science, 1973, 10, 75.

10 Wang, S P, and Grayston, J T, in Trachoma and Related Disorders Caused by Chlamydial Agents, ed R L Nichols, p 217. Amsterdam and New York, Excerpta Medica, 1971.

\title{
Contraceptive steroids and breast cancer
}

\author{
J D SPENCER, ROSEMARY R MILLIS, J L HAYWARD
}

British Medical fournal, 1978, 1, 1024-1026

\section{Summary and conclusions}

The prognosis and pathological findings in 44 patients with breast cancer who had taken contraceptive steroids during the year before diagnosis were compared with those in 44 controls matched for age and parity. No significant differences between the two groups were

\footnotetext{
Imperial Cancer Research Fund Breast Cancer Unit, Guy's Hospital, London SE1 9RT

J D SPENCER, MRCP, FRCS, senior surgical registrar (now at department of orthopaedic surgery)

ROSEMARY R MILLIS, MRCPATH, consultant pathologist

J L HAYWARD, FRCS, director
}

found in the histological features of the tumour or extent of axillary lymph-node disease. In patients with axillary node disease the recurrence rate in the controls was significantly higher than in the study group and more of the control patients had died.

It is concluded that oral contraceptives have no untoward effect on the prognosis of breast cancer.

\section{Introduction}

It has been suggested that steroidal oral contraceptives may affect the pathogenesis and rate of growth of breast cancers. Most of these agents contain small amounts of oestrogenic steroids and it is widely believed that low doses of oestrogen may accelerate the rate of growth of breast tumours, though this assumption is based only on experiments with laboratory animals and on a few anecdotal cases concerning women with the disease. $^{1-3}$ Indeed, a trial using small doses of stilboestrol 